\title{
Effectiveness of the influenza vaccine in preventing admission to hospital and death in people with type 2 diabetes
}

\author{
Eszter P. Vamos MD PhD, Utz J. Pape PhD, Vasa Curcin MSc PhD, Matthew J. Harris DPhil, Jonathan \\ Valabhji MD, Azeem Majeed MD, Christopher Millett PhD
}

Competing interests: None declared.

This article has been peer reviewed.

Accepted: May 2, 2016

Online: July 25, 2016

Correspondence to: Eszter Vamos, e.vamos@imperial. ac.uk

CMAJ 2016. DOI:10.1503/ cmaj.151059

\begin{abstract}
Background: The health burden caused by seasonal influenza is substantial. We sought to examine the effectiveness of influenza vaccination against admission to hospital for acute cardiovascular and respiratory conditions and all-cause death in people with type 2 diabetes.
\end{abstract}

Methods: We conducted a retrospective cohort study using primary and secondary care data from the Clinical Practice Research Datalink in England, over a 7-year period between 2003/04 and 2009/10. We enrolled 124503 adults with type 2 diabetes. Outcome measures included admission to hospital for acute myocardial infarction (MI), stroke, heart failure or pneumonia/influenza, and death. We fitted Poisson regression models for influenza and off-season periods to estimate incidence rate ratios (IRR) for cohorts who had and had not received the vaccine. We used estimates for the summer, when influenza activity is low, to adjust for residual confounding.

$\mathrm{T}$ he health burden caused by seasonal influenza in the general population is substantial and explains much of the excess winter mortality. ${ }^{1-3}$ Influenza infection may accelerate acute thrombotic vascular events, particularly in patients with ischemic heart disease and cerebrovascular disease. ${ }^{4}$ For decades, vaccination has been the principal strategy to control influenza and its severe complications in older adults and patients with chronic illnesses, who account for most influenza-attributable deaths. ${ }^{1}$ Current influenza vaccination programs were implemented based on studies that involved healthy adults in the 1960s, which suggested $70 \%-90 \%$ vaccine efficacy. ${ }^{5}$ In European countries, vaccination is generally restricted to older adults and adults with chronic conditions, and their close contacts to reduce transmission. ${ }^{6}$ In North America, annual influenza vaccination is universally recommended for all people aged 6 months and older. ${ }^{7.8}$
Results: Study participants contributed to 623591 person-years of observation during the 7-year study period. Vaccine recipients were older and had more comorbid conditions compared with nonrecipients. After we adjusted for covariates and residual confounding, vaccination was associated with significantly lower admission rates for stroke (IRR $0.70,95 \%$ confidence interval $[\mathrm{Cl}] 0.53-0.91$ ), heart failure (IRR $0.78,95 \% \mathrm{Cl} 0.65-0.92$ ) and pneumonia or influenza (IRR $0.85,95 \% \mathrm{Cl}$ $0.74-0.99$ ), as well as all-cause death (IRR 0.76 , $95 \% \mathrm{Cl} 0.65-0.83)$, and a nonsignificant change for acute MI (IRR $0.81,95 \% \mathrm{Cl} 0.62$ 1.04) during the influenza seasons.

Interpretation: In this cohort of patients with type 2 diabetes, influenza vaccination was associated with reductions in rates of admission to hospital for specific cardiovascular events. Efforts should be focused on improvements in vaccine uptake in this important target group as part of comprehensive secondary prevention.
There is uncertainty about the degree of influenza vaccine protection in groups at increased risk and older adults despite being target populations within many national immunization schedules. ${ }^{9}$ This controversy has been fed by a number of concerns. First, more recent and methodologically sound studies have reported considerably lower vaccine efficacy in healthy people than was reported in earlier studies. ${ }^{9}$ Second, although evidence from placebo-controlled randomized clinical trials shows the effectiveness of influenza vaccine against infection in young people and healthy older adults, there is no compelling clinical trial evidence to suggest similar benefits in older adults with chronic illness. ${ }^{10}$

For people with diabetes, an especially highrisk group for influenza-related complications, concerns have been raised about impaired immune response to influenza vaccine. ${ }^{11}$ Given that national guidelines now strongly recom- 
mend influenza vaccination for older adults and patients with chronic illness in many countries, placebo-controlled clinical trials involving patients with high cardiovascular risk may not receive ethical approval. ${ }^{9}$ A few small clinical trials have tested whether receipt of the influenza vaccine might reduce cardiovascular risk in patients with pre-existing cardiovascular disease. ${ }^{12}$ However, none of these were adequately powered to assess effects on mortality and specific cardiovascular outcomes. ${ }^{12}$ Furthermore, methodological studies highlight potential flaws in observational studies, including inadequate adjustment for systematic differences between vaccine recipients and nonrecipients (referred to as "residual confounding")., ${ }^{9,13}$

Studies assessing influenza vaccine effectiveness in people with diabetes are scarce and have shown inconclusive results. ${ }^{11}$ None of the previous studies adjusted for residual confounding, and most of them reported composite end-points such as admission to hospital for any cause. Furthermore, we are not aware of any studies assessing the potential benefits of influenza vaccination against individual cardiovascular events in people with type 2 diabetes. ${ }^{11,14}$

The primary aim of our study was to assess the effectiveness of seasonal influenza vaccine against hospital admissions for acute myocardial infarction (MI), stroke and heart failure in patients with type 2 diabetes, while assessing and making further adjustments for residual confounding using estimates obtained for the summer, when influenza activity is minimal. We also assessed the association between influenza vaccine and hospital admission for pneumonia or influenza and all-cause death.

\section{Methods}

\section{Study population}

We used the Clinical Practice Research Datalink in England for this study. This database is one of the world's largest computerized medical databases holding prospective primary care records..$^{15,16}$ Anonymized primary care data for English practices in the database are now available with a linkage to non-primary care records, including Hospital Episode Statistics data and Office for National Statistics mortality files. ${ }^{16}$ The number of practices participating in the data linkage is 300 , representing $65 \%$ of participating practices and 5\% of England's general population. ${ }^{16}$

We obtained an extract of the records of adults with type 2 diabetes registered with the 300 family practices participating in the data linkage between 2003/04 and 2009/10. Patients with type 2 diabetes were identified using both diagnostic
(C10) and management (66A) read codes for type 2 diabetes. ${ }^{17}$ Participants for the first cohort year from Sept. 1, 2003, to Aug. 31, 2004, included patients with diabetes who were at least 18 years of age on Sept. 1, 2003, and had been continuously registered with participating practices during the preceding 12 months and throughout the cohort year. For each following study year, patients who newly met the eligibility criteria on September 1 were enrolled. Ethics approval for the study protocol was obtained from the Independent Scientific Advisory Committee of the Clinical Practice Research Datalink.

\section{Study periods}

Each cohort year was categorized into 4 periods: preinfluenza, influenza season, postinfluenza and summer. Dates of the onset and end of influenza season were obtained for each year from national surveillance data on weekly general practitioner consultation rates for influenza-like illness. ${ }^{18}$ According to this surveillance system, influenza season starts when these weekly consultation rates exceed the threshold of 30 per 100000 population and ends when activity goes below this threshold. ${ }^{19}$ We further defined influenza season as the period from the date of onset to 4 weeks after the end of influenza season to capture delayed complications.

We defined preinfluenza season as the time period from September 1 to the date of onset of the influenza season. We defined postinfluenza season as the period after the influenza season to Apr. 30. We defined the summer period as May 1 to Aug. 31 for each cohort year. Preinfluenza, influenza, postinfluenza and summer periods were combined across all study years between 2003/04 and 2009/10.

\section{Outcome measures}

Our outcomes included hospital admissions for acute MI, stroke, pneumonia or influenza and heart failure, as well as all-cause death. Hospital admissions were identified from Hospital Episode statistics as the principal diagnosis on admission using International Statistical Classification of Diseases and Related Health Problems, 10th Revision (ICD-10), codes as follows: acute MI, I21-I22; stroke, I60-I64; influenza or pneumonia, J09-J18; and heart failure, I50. During each cohort year, patients were followed from September 1 until either the occurrence of study outcomes or the end of cohort year (Aug. 31).

Baseline data obtained for each cohort year included age, sex, smoking status (classified as current smoker, former smoker, nonsmoker or missing), body mass index (BMI), laboratory 
tests (cholesterol and glycated hemoglobin $\left.\left[\mathrm{HbA}_{1 \mathrm{c}}\right]\right)$, systolic and diastolic blood pressures and number of hospital admissions during the preceding 12 months. We defined baseline comorbid conditions using diagnostic read codes and included history of MI, stroke, heart failure, asthma, chronic obstructive pulmonary disease, chronic kidney disease, cancer and atrial fibrillation. We identified medications prescribed from prescription records: insulin, oral antihyperglycemic agents, antihypertensive agents, lipid-lowering agents, anticoagulants and antiplatelet drugs, and immunosuppressants. We assigned a deprivation score to individual patients using the Index of Multiple Deprivation 2004 based on the postal code of the practice to which they were registered ${ }^{20}$ All covariates were redefined at the beginning of each cohort year.

\section{Vaccination status}

Influenza vaccination status was determined from primary care records for each year. In 2009/10, there was an outbreak of a pandemic influenza $\mathrm{A}(\mathrm{H} 1 \mathrm{~N} 1)$ pdm09 virus. ${ }^{18}$ Owing to some unspecific codes that do not allow discrimination between seasonal and pandemic influenza vaccination, we included all influenza vaccination codes for 2009 and 2010. All study participants were classified as not having received the vaccine from September 1 until they received vaccine for the subject year. Patients were classified as having been effectively vaccinated 14 days after the date of vaccination to allow for the attainment of protective antibody titres. ${ }^{21}$ We also obtained information on history of pneumococcal polysaccharide vaccination and influenza vaccination during the previous year.

\section{Statistical analysis}

We compared baseline characteristics of vaccinated and unvaccinated study participants using the $\chi^{2}$ test for categorical variables, Student $t$ test for normally distributed variables and MannWhitney test for skewed continuous variables.

To estimate incidence rate ratios (IRR) with 95\% confidence intervals (CI) for vaccinated versus unvaccinated cohorts, we fitted random effects Poisson regression models for each outcome. We performed 3 sets of models for each study outcome and each study period separately: unadjusted (vaccination status as the only predictor), models adjusted for study covariates and models for the influenza period additionally adjusted for residual confounding.

Covariates in the adjusted models included age, sex, index of multiple deprivation quintile, duration of diabetes, number of comorbid condi- tions, smoking status, medications (lipid-lowering drugs, anticoagulant or antiplatelet drugs, antihypertensive drugs, insulin, oral antihyperglycemic drugs and immunosuppressive drugs), systolic blood pressure, diastolic blood pressure, BMI, serum $\mathrm{HbA}_{\mathrm{lc}}$, serum cholesterol, number of hospital admissions, influenza vaccination during the previous year, history of pneumococcal vaccination and cohort year.

We considered vaccine status a time-varying exposure, and each patient's follow-up time was classified into vaccinated and unvaccinated person-time periods. We included follow-up time in the models as an offset term. Study participants could contribute to more than one cohort year in this study. To account for potential within-person dependency, we entered patients as random effects into the models.

We performed an additional analysis to obtain unadjusted and adjusted IRRs and 95\% CIs that excluded cohort year 2008/09, when an outbreak of the influenza $\mathrm{A}(\mathrm{H} 1 \mathrm{~N} 1) \mathrm{pdm} 09$ pandemic strain occurred, to test whether the exclusion of this year affected our results.

\section{Adjustment for residual confounding}

Given that influenza activity is minimal during the summer, vaccination should not provide benefits during the off-season. ${ }^{22,23}$ Therefore, patients who have and who have not received vaccine should have similar risks of outcomes during the summer period after adjustment for measured confounders, with an expected IRR of 1.0 for the summer period. We used effect estimates for the summer period to adjust for residual confounding that occurred during the influenza period using the following formula: $:^{23,24}$

$$
I R R_{\text {adjusted }}=\exp \left(\beta_{\text {influenza season }}-\beta_{\text {summer period }}\right)
$$

where $\beta$ is the regression coefficient obtained from Poisson regression models. To calculate 95\% CIs for the effect estimates, we resampled 500 times from the distribution of the observed estimates for the influenza and summer periods. After having taken the difference of each of the 500 sampled estimates, the 2.5 th and 97.5 th percentile of the distribution were taken to obtain $95 \%$ CIs for the adjusted IRRs. ${ }^{23,24}$

In all analyses, a 2-sided $p \leq 0.05$ was considered statistically significant. We performed statistical analyses using Stata version 11.0.

\section{Results}

This study included 124503 patients with type 2 diabetes who contributed to 623591 personyears of observation during the 7-year study 
period. During this period, the predominant circulating influenza strains were A(H3N2) in 2003/04, 2004/05, 2006/07 and 2008/09, B in 2005/06 and A(H1N1) in 2007/08 and 2009/10 (Table 1). ${ }^{18}$ The antigenic match between the circulating and vaccine strains was good for all study years, except for 2003/04 owing to antigenic drift and $2009 / 10$ owing to the occurrence of a new variant as a result of antigenic shift. ${ }^{18}$ Overall seasonal influenza vaccination uptake in the cohort ranged from $63.1 \%$ in $2008 / 09$ to $69.0 \%$ in $2006 / 07$. Across all study years, there were 5142 hospital admissions for acute MI, 4515 admissions for stroke, 14154 admissions for pneumonia or influenza, 12915 admissions for heart failure and 21070 deaths.

Table 2 shows the baseline characteristics of vaccine recipients and nonrecipients for the 2003/04 and 2009/10 cohorts. Vaccine recipients were older and generally more ill, had more coexisting conditions and a larger number of medica- tions prescribed, but had lower levels of $\mathrm{HbA}_{1 \mathrm{c}}$ and cholesterol compared with nonrecipients.

In unadjusted analyses, there was an inconsistent association between vaccination and outcomes during the influenza season. Compared with nonrecipients, vaccine recipients had significantly higher rates of hospital admission for acute MI and heart failure and lower rates of death; rates did not significantly differ for stroke or pneumonia (Table 3). Vaccination was associated with higher event rates during the summer for all outcomes.

Adjusting the models for study covariates attenuated IRRs for all study outcomes compared with unadjusted IRRs. Influenza vaccination was associated with significant reductions in all outcomes during the influenza season (Table 3). Vaccine recipients had $22 \%$ lower rates of acute MI (IRR 0.78, 95\% CI 0.65-0.93, $p<0.01), 17 \%$ reduction in rates of heart failure (IRR $0.83,95 \%$ CI $0.74-0.93, p<0.001)$ and $25 \%$ lower rates for

Table 1: Characteristics of study cohort years from 2003-2004 to 2009-2010

\begin{tabular}{|c|c|c|c|c|c|c|c|}
\hline \multirow[b]{2}{*}{ Characteristic } & \multicolumn{7}{|c|}{ Study cohort year } \\
\hline & $2003 / 04$ & $2004 / 05$ & $2005 / 06$ & $2006 / 07$ & $2007 / 08$ & 2008/09 & $2009 / 10$ \\
\hline \multicolumn{8}{|c|}{ Influenza season week (date) } \\
\hline Date of onset & 46 (13 Nov.) & 1 (6 Jan.) & 5 (27 Jan.) & 5 (26 Jan.) & 1 (31 Dec.) & 50 (5 Dec.) & 42 (9 Oct.) \\
\hline End date & 49 (5 Dec.) & 6 (11 Feb.) & 8 (23 Feb.) & 9 (1 Mar.) & 2 (13 Jan.) & 3 (15 Jan.) & 49 (3 Dec.) \\
\hline $\begin{array}{l}\text { No. of patients } \\
\text { entering the cohort }\end{array}$ & 67067 & 76215 & 84780 & 92732 & 100187 & 107323 & 107013 \\
\hline Total person-years & 66157.3 & 74779.1 & 83111.6 & 90951.3 & 98488.5 & 105218.2 & 104884.6 \\
\hline \multicolumn{8}{|l|}{ No. of hospital admissions } \\
\hline Acute MI & 639 & 676 & 713 & 725 & 798 & 816 & 775 \\
\hline Stroke & 518 & 561 & 635 & 654 & 702 & 749 & 696 \\
\hline $\begin{array}{l}\text { Pneumonia or } \\
\text { influenza }\end{array}$ & 1233 & 1560 & 1761 & 2021 & 2267 & 2626 & 2686 \\
\hline Heart failure & 1312 & 1503 & 1713 & 1783 & 2045 & 2224 & 2335 \\
\hline $\begin{array}{l}\text { No. of deaths (all } \\
\text { causes) }\end{array}$ & 1899 & 2507 & 2903 & 3124 & 3390 & 3611 & 3636 \\
\hline Vaccine coverage, \% & 66.54 & 68.4 & 69 & 65.7 & 63.9 & 63.1 & 65 \\
\hline $\begin{array}{l}\text { Vaccination coverage } \\
\text { among recipients by } \\
\text { start of influenza } \\
\text { season, \% }\end{array}$ & 86.1 & 97.7 & 98.9 & 98.5 & 97.3 & 94 & 37.8 \\
\hline $\begin{array}{l}\text { Predominant influenza } \\
\text { strain }\end{array}$ & $\mathrm{A}(\mathrm{H} 3 \mathrm{~N} 2)$ & $\mathrm{A}(\mathrm{H} 3 \mathrm{~N} 2)$ & B & $\mathrm{A}(\mathrm{H} 3 \mathrm{~N} 2)$ & $\mathrm{A}(\mathrm{H} 1 \mathrm{~N} 1)$ & $\mathrm{A}(\mathrm{H} 3 \mathrm{~N} 2)$ & $\mathrm{A}(\mathrm{H} 1 \mathrm{~N} 1)$ \\
\hline $\begin{array}{l}\text { Predominant virus } \\
\text { subtype }\end{array}$ & $\begin{array}{c}\text { Fujian/411/ } \\
2002\end{array}$ & $\begin{array}{l}\text { Wellington/01/ } \\
2004\end{array}$ & $\begin{array}{l}\text { Hong Kong/ } \\
330 / 2001\end{array}$ & $\begin{array}{l}\text { Wisconsin/ } \\
67 / 05\end{array}$ & $\begin{array}{l}\text { Solomon Island } \\
\qquad / 3 / 2006\end{array}$ & $\begin{array}{l}\text { Brisbane/ } \\
10 / 2007\end{array}$ & $\begin{array}{c}\text { California/ } \\
07 / 2009\end{array}$ \\
\hline $\begin{array}{l}\text { Vaccine-virus antigenic } \\
\text { match }\end{array}$ & Low & Good & Good & Good & Good & Good & No match \\
\hline
\end{tabular}


pneumonia or influenza (IRR $0.75,95 \%$ CI 0.68 $0.82, p<0.001$ ); the IRR for stroke was 0.82 (95\% CI 0.66-1.00). Furthermore, vaccination reduced mortality by $50 \%$ during influenza season (IRR 0.50, 95\% CI 0.45-0.54, $p<0.001$ ). Vaccination was also associated with signifi- cantly lower event rates during the pre and postinfluenza seasons for all outcomes except acute MI and pneumonia or influenza in the preinfluenza period (Table 3). However, estimates for the summer period showed differences between vaccine recipients and nonrecipients in

Table 2: Characteristics of participants at baseline during the $2003 / 04$ and $2009 / 10$ cohort years

\begin{tabular}{|c|c|c|c|c|c|c|}
\hline \multirow[b]{3}{*}{ Characteristic } & \multicolumn{6}{|c|}{ No. $(\%)$ * } \\
\hline & \multicolumn{3}{|c|}{ Influenza vaccine 2003/04 } & \multicolumn{3}{|c|}{ Influenza vaccine 2009/10 } \\
\hline & Yes & No & $p$ & Yes & No & $p$ \\
\hline Participants & 44604 (66.5) & 22463 (33.5) & - & $69594(65.0)$ & $37419(35.0)$ & - \\
\hline Age, yr, mean $\pm S D$ & $66.2 \pm 13.3$ & $56.2 \pm 16.3$ & $<0.001 \dagger$ & $65.8 \pm 13.8$ & $58.4 \pm 17.2$ & $<0.001 \dagger$ \\
\hline \multicolumn{7}{|l|}{ Age group, yr } \\
\hline$<65$ & 17309 (38.8) & $15517(69.1)$ & $<0.001 \ddagger$ & $29463(42.3)$ & $22875(61.1)$ & $<0.001 \neq$ \\
\hline $65-70$ & $8676(19.5)$ & $2319(10.3)$ & & $11470(16.5)$ & $4491(12.0)$ & \\
\hline $71-80$ & $14006(31.4)$ & 3229 (14.4) & & $20612(29.6)$ & $6581(17.6)$ & \\
\hline$\geq 81$ & $4613(10.3)$ & $1398(6.2)$ & & $8049(11.6)$ & $3472(9.3)$ & \\
\hline Male sex & $24038(53.9)$ & $12179(54.2)$ & & $38190(54.9)$ & $18971(50.7)$ & \\
\hline Smoking status & & & $<0.001 \ddagger$ & & & $<0.001 \mp$ \\
\hline Current smoker & $5454(12.2)$ & $4442(19.8)$ & $<0.001 \ddagger$ & $8455(12.2)$ & $7087(18.9)$ & $<0.001 \neq$ \\
\hline Nonsmoker & 20774 (46.6) & $10074(44.8)$ & & $33533(48.2)$ & $17679(47.2)$ & \\
\hline Former smoker & 16915 (37.9) & $5996(26.7)$ & & 27515 (39.5) & $10937(29.2)$ & \\
\hline Missing data & $1461(3.3)$ & $1951(8.7)$ & & $91(0.1)$ & $1716(4.6)$ & \\
\hline $\mathrm{BMI}$, mean $\pm \mathrm{SD}$ & $29.5 \pm 6.0$ & $30.1 \pm 6.5$ & $<0.001 \dagger$ & $30.5 \pm 6.4$ & $30.5 \pm 6.9$ & $0.137 \dagger$ \\
\hline $\begin{array}{l}\text { Cholesterol, } \mathrm{mmol} / \mathrm{L} \\
\text { mean } \pm \mathrm{SD}\end{array}$ & $4.7 \pm 1.0$ & $5.0 \pm 1.1$ & $<0.001 \dagger$ & $4.3 \pm 1.0$ & $4.6 \pm 1.1$ & $<0.001 \dagger$ \\
\hline $\mathrm{SBP}, \mathrm{mm} \mathrm{Hg}$, mean $\pm \mathrm{SD}$ & $141.0 \pm 15.9$ & $138.9 \pm 17.9$ & $<0.001 \dagger$ & $135.5 \pm 14.2$ & $134.9 \pm 16.6$ & $<0.001 \uparrow$ \\
\hline $\mathrm{DBP}, \mathrm{mm} \mathrm{Hg}$, mean $\pm \mathrm{SD}$ & $77.9 \pm 8.5$ & $80.4 \pm 9.8$ & $<0.001 \dagger$ & $75.9 \pm 8.6$ & $78.2 \pm 9.7$ & $<0.001 \uparrow$ \\
\hline $\mathrm{HbA}_{1 c} \%$, mean $\pm \mathrm{SD}$ & $7.5 \pm 1.41$ & $7.9 \pm 1.80$ & $<0.001 \dagger$ & $7.3 \pm 1.4$ & $7.7 \pm 1.80$ & $<0.001 \dagger$ \\
\hline $\begin{array}{l}\text { No. of comorbid conditions, } \\
\text { median (IQR) }\end{array}$ & $(0-2)$ & $(0-1)$ & $<0.001 \S$ & $1(0-2)$ & $(0-1)$ & $<0.001 \S$ \\
\hline \multicolumn{7}{|l|}{ Recorded clinical history } \\
\hline Heart failure & $4503(10.1)$ & $990(4.4)$ & $<0.001 \ddagger$ & 4578 (6.6) & $1616(4.3)$ & $<0.001 \ddagger$ \\
\hline Stroke & $1857(4.2)$ & $1504(6.7)$ & $<0.001 \ddagger$ & 6525 (9.4) & 2604 (6.9) & $<0.001 \neq$ \\
\hline Myocardial infarction & $3731(8.4)$ & $1313(5.8)$ & $<0.001 \ddagger$ & $3028(8.7)$ & $2121(5.7)$ & $<0.001 \neq$ \\
\hline COPD & $4750(10.6)$ & $410(1.8)$ & $<0.001 \ddagger$ & $4631(6.6)$ & $1203(3.2)$ & $<0.001 \neq$ \\
\hline Asthma & $5900(13.2)$ & $2377(10.6)$ & $<0.001 \ddagger$ & $10348(14.9)$ & $4738(12.7)$ & $<0.001 \neq$ \\
\hline Cancer & $2524(5.7)$ & $773(3.4)$ & $<0.001 \ddagger$ & $4844(7.0)$ & $1627(4.3)$ & $<0.001 \neq$ \\
\hline Atrial fibrillation & $3280(7.3)$ & 785 (3.5) & $<0.001 \ddagger$ & $5439(7.8)$ & 1730 (4.6) & $<0.001 \mp$ \\
\hline Chronic kidney disease & $2276(5.1)$ & $625(2.8)$ & $<0.001 \ddagger$ & $19164(27.5)$ & $5811(15.5)$ & $<0.001 \neq$ \\
\hline \multicolumn{7}{|l|}{ Medication } \\
\hline Oral antihyperglycaemic drug & $28007(62.8)$ & 10438 (46.5) & $<0.001 \neq$ & $49302(70.8)$ & 25305 (67.6) & $<0.001 \ddagger$ \\
\hline Insulin & 9782 (21.9) & $4589(20.4)$ & $<0.001 \neq$ & $14911(21.4)$ & 8555 (22.9) & $<0.001 \ddagger$ \\
\hline \multicolumn{7}{|l|}{ Antihypertensive agent } \\
\hline ACE or ARB & $24476(54.9)$ & 7779 (34.6) & $<0.001 \ddagger$ & $49092(70.5)$ & $19826(53.0)$ & $<0.001 \neq$ \\
\hline$\beta$-blocker & 16215 (36.4) & $5547(24.7)$ & $<0.001 \ddagger$ & $28999(71.8)$ & $11402(30.5)$ & $<0.001 \neq$ \\
\hline Other & 27897 (62.5) & 8880 (39.5) & $<0.001 \neq$ & $46316(66.5)$ & $18350(49.0)$ & $<0.001 \ddagger$ \\
\hline Lipid-lowering agent & $22301(50.0)$ & $7083(31.5)$ & $<0.001 \ddagger$ & $57228(82.2)$ & $23406(62.5)$ & $<0.001 \neq$ \\
\hline Anticoagulant/antiplatelet drug & $22315(50.0)$ & $6458(28.7)$ & $<0.001 \ddagger$ & $43354(62.3)$ & $16875(45.1)$ & $<0.001 \neq$ \\
\hline Immunosuppressant & $687(1.5)$ & $224(1.0)$ & $<0.001 \ddagger$ & $1517(2.2)$ & 499 (1.3) & $<0.001 \ddagger$ \\
\hline $\begin{array}{l}\text { No. of medications, median } \\
\text { (IQR) }\end{array}$ & $4(2-6)$ & $2(1-4)$ & $<0.001 \S$ & $5(3-7)$ & $4(2-6)$ & $<0.001 \S$ \\
\hline $\begin{array}{l}\text { Hospital admissions during past } \\
\text { year, no. }(\%)\end{array}$ & $11552(25.8)$ & $4726(21.0)$ & $<0.001 \ddagger$ & $19531(28.1)$ & $9579(25.6)$ & $<0.001 \ddagger$ \\
\hline $\begin{array}{l}\text { Pneumococcal vaccine during } \\
\text { past } 5 \mathrm{yr} \text {, no. (\%) }\end{array}$ & 15995 (35.9) & $2638(11.7)$ & $<0.001 \ddagger$ & $28904(41.5)$ & $7627(20.4)$ & $<0.001 \neq$ \\
\hline $\begin{array}{l}\text { Influenza vaccine during past } \\
\text { year, no. (\%) }\end{array}$ & 35940 (80.6) & $3473(15.5)$ & $<0.001 \ddagger$ & $60016(86.2)$ & $7110(19.0)$ & $<0.001 \ddagger$ \\
\hline 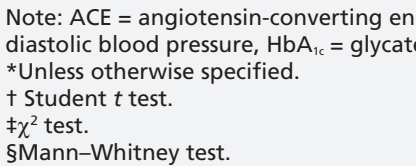 & $\begin{array}{l}\text { e, ARB = angi } \\
\text { emoglobin, }\end{array}$ & terquartile ra & $\begin{array}{l}=\text { body } \mathrm{m} \\
=\text { systolic }\end{array}$ & $\begin{array}{l}x, C O P D=\text { chro } \\
\text { essure, } S D=\text { sta }\end{array}$ & $\begin{array}{l}\text { tructive pulmor } \\
\text { deviation. }\end{array}$ & ase, DBP = \\
\hline
\end{tabular}


these models, suggesting insufficient adjustment for underlying differences between these groups.

After adjustment for residual confounding, vaccination was associated with a $19 \%$ reduction in the rate of hospital admissions for acute MI (IRR $0.81,95 \%$ CI 0.62-1.04), 30\% for stroke (IRR $0.70,95 \%$ CI $0.53-0.91$ ), 22\% for heart failure (IRR $0.78,95 \%$ CI $0.65-0.92$ ) and $15 \%$ for pneumonia or influenza (IRR $0.85,95 \%$ CI 0.74 0.99) during influenza season among people with diabetes who received the vaccine compared with those who did not (Figure 1). In addition, patients who received the vaccine had $24 \%$ lower death rates compared with nonrecipients (IRR 0.76, 95\% CI 0.65-0.83).

Excluding cohort year 2008/09 from the analysis when the pandemic $\mathrm{A}(\mathrm{H} 1 \mathrm{~N} 1) \mathrm{pdm} 09$ was circulating did not qualitatively change the unadjusted and adjusted IRRs obtained for the flu and summer periods (Table 4).

\section{Interpretation}

In this large population-based study, influenza vaccination in people with type 2 diabetes was associated with reductions in rates of hospital admission for acute cardiovascular and respiratory diseases, and in all-cause mortality across 7 influenza seasons. Additional adjustment for residual confounding did not qualitatively alter the results of the conventional analyses but attenuated the associations for acute MI, pneumonia or influenza and death, and strengthened the associations for stroke and heart failure. Influenza

Table 3: Risk of admission to hospital among people with type 2 diabetes who received influenza vaccination compared with those who did not receive vaccination for periods before, during and after influenza season and during the summer across all study years $(2003 / 04$ to $2009 / 10)$

\begin{tabular}{|c|c|c|c|c|c|c|c|c|c|c|}
\hline \multirow[b]{2}{*}{ Outcome } & \multirow[b]{2}{*}{$\begin{array}{c}\text { Study } \\
\text { period* }\end{array}$} & \multicolumn{3}{|c|}{ Vaccinated } & \multicolumn{3}{|c|}{ Unvaccinated } & Unadjusted model‡ & \multicolumn{2}{|c|}{ Adjusted model§ } \\
\hline & & $\begin{array}{l}\text { No. of } \\
\text { events }\end{array}$ & PY & Rate† & $\begin{array}{l}\text { No. of } \\
\text { events }\end{array}$ & PY & Rate† & IRR (95\% CI) & & $\mathrm{R}(95 \% \mathrm{Cl})$ \\
\hline \multirow{4}{*}{$\begin{array}{l}\text { Hospital } \\
\text { admissions for } \\
\text { acute } \\
\text { myocardial } \\
\text { infarction }\end{array}$} & Preinfluenza & 452 & 49181.9 & 9.19 & 1174 & 135674.6 & 8.65 & $(0.95-1.18)$ & 0.91 & $(0.81-1.03)$ \\
\hline & Influenza & 580 & 64633.9 & 8.97 & 329 & 43597.7 & 7.55 & (1.03-1.36)ף & 0.78 & $(0.65-0.93)^{* *}$ \\
\hline & Postinfluenza & 712 & 80677.7 & 8.83 & 316 & 43305.6 & 7.30 & $(1.05-1.38)^{* *}$ & 0.87 & $(0.71-1.05)$ \\
\hline & Summer & 1133 & 139014.5 & 8.15 & 446 & 72567.9 & 6.15 & $(1.18-1.47) \dagger \dagger$ & 0.96 & $(0.82-1.12)$ \\
\hline \multirow{4}{*}{$\begin{array}{l}\text { Hospital } \\
\text { admissions for } \\
\text { stroke }\end{array}$} & Preinfluenza & 323 & 49210.8 & 6.56 & 1102 & 135678.7 & 8.12 & $0.81 \quad(0.71-0.91) \dagger \dagger$ & 0.74 & $(0.65-0.85) \dagger \dagger$ \\
\hline & Influenza & 486 & 64688.4 & 7.51 & 310 & 43594.4 & 7.11 & $(0.91-1.21)$ & 0.82 & $(0.67-1.00)$ \\
\hline & Postinfluenza & 559 & 80768.3 & 6.92 & 331 & 43291.6 & 7.65 & $(0.78-1.03)$ & 0.73 & $(0.59-0.89) * *$ \\
\hline & Summer & 1046 & 139220.9 & 7.51 & 358 & 72555.7 & 4.93 & $(1.35-1.73)+\dagger$ & 1.17 & $(1.00-1.41)$ \\
\hline \multirow{4}{*}{$\begin{array}{l}\text { Hospital } \\
\text { admission for } \\
\text { heart failure }\end{array}$} & Preinfluenza & 1180 & 49005.6 & 24.08 & 3199 & 135431.5 & 23.62 & $(0.92-1.06)$ & 0.88 & $(0.82-0.95) \dagger+$ \\
\hline & Influenza & 1617 & 64288.5 & 25.15 & 813 & 43412.2 & 18.73 & $(1.17-1.40) \dagger \dagger$ & 0.83 & $(0.74-0.93) \dagger \dagger$ \\
\hline & Postinfluenza & 1790 & 80067.4 & 22.36 & 676 & 43008.7 & 15.72 & $(1.27-1.53)+\dagger$ & 0.84 & $(0.73-0.95)^{* *}$ \\
\hline & Summer & 2770 & 137484.2 & 20.15 & 870 & 71943.3 & 12.09 & (1.52-1.79)†† & 1.06 & $(0.95-1.18)$ \\
\hline \multirow{4}{*}{$\begin{array}{l}\text { Hospital } \\
\text { admission for } \\
\text { pneumonia/ } \\
\text { influenza }\end{array}$} & Preinfluenza & 1245 & 49076.0 & 25.37 & 3007 & 135478.0 & 22.20 & (1.07-1.23)†† & 1.08 & $1.17)^{* *}$ \\
\hline & Influenza & 1908 & 64331.7 & 29.66 & 1307 & 43326.2 & 30.17 & $(0.89-1.03)$ & 0.75 & $(0.68-0.82) \dagger \dagger$ \\
\hline & Postinfluenza & 1989 & 80081.9 & 24.84 & 919 & 42845.0 & 21.45 & $(1.06-1.25)+\dagger$ & 0.86 & $(0.77-0.97)$ ** \\
\hline & Summer & 2623 & 137505.4 & 19.08 & 1156 & 71571.1 & 16.15 & $(1.10-1.27) \dagger \dagger$ & 0.88 & П) \\
\hline \multirow{4}{*}{$\begin{array}{l}\text { All-cause } \\
\text { mortality }\end{array}$} & Preinfluenza & 1381 & 49243.8 & 28.04 & 4441 & 135812.9 & 32.70 & $(0.81-0.91) \dagger \dagger$ & 0.77 & $(0.72-0.83) \dagger \dagger$ \\
\hline & Influenza & 2294 & 64569.0 & 35.53 & 1797 & 43029.2 & 41.76 & $(0.80-0.90)+\dagger$ & 0.50 & $(0.45-0.54)+\dagger$ \\
\hline & Postinfluenza & 2838 & 80362.3 & 35.32 & 1464 & 42403.0 & 34.53 & $(0.96-1.09)$ & 0.58 & $(0.52-0.65)+\dagger$ \\
\hline & Summer & 4732 & 137644.4 & 34.38 & 2123 & 70526.3 & 30.10 & $1.14 \quad(1.08-1.20)+t$ & 0.66 & $(0.61-0.72)+\dagger$ \\
\hline \multicolumn{11}{|c|}{$\begin{array}{l}\text { Note: } \mathrm{Cl}=\text { confidence interval, IRR }=\text { incidence rate ratio, } \mathrm{PY}=\text { person-years. } \\
\text { *Preinfluenza season was defined as the period from Sept. } 1 \text { to the onset of the influenza season. Influenza season was defined as the period from the ons } \\
\text { the end of the influenza season, with an additional } 4 \text { weeks to capture delayed complications. Postinfluenza season was defined as the period after the infl } \\
\text { season to Apr. } 30 \text { each year. Summer was defined as May } 1 \text { to Aug. } 31 \text { for each cohort year. } \\
\text { tRates are expressed as per } 1000 \text { patient years. } \\
\text { fModels with vaccination status as the only predictor. } \\
\text { SModels are adjusted for age, sex, index of multiple deprivation quintile, number of comorbid conditions, duration of diabetes, body mass index, smoking } \\
\text { status, systolic and diastolic blood pressure, serum cholesterol and glycated hemoglobin, use of lipid-lowering drugs, anticoagulants or antiplatelet drugs, } \\
\text { antihypertensive drugs, insulin, oral antihyperglycemic drugs or immunosuppressive drugs, number of hospital admissions during previous year, history of } \\
\text { pneumococcal vaccination, influenza vaccination during previous year and cohort year. } \\
\text { ๆ } p \leq 0.05 \text {. } \\
* * p \leq 0.01 \text {. } \\
+\dagger p \leq 0.001 \text {. }\end{array}$} \\
\hline
\end{tabular}


A

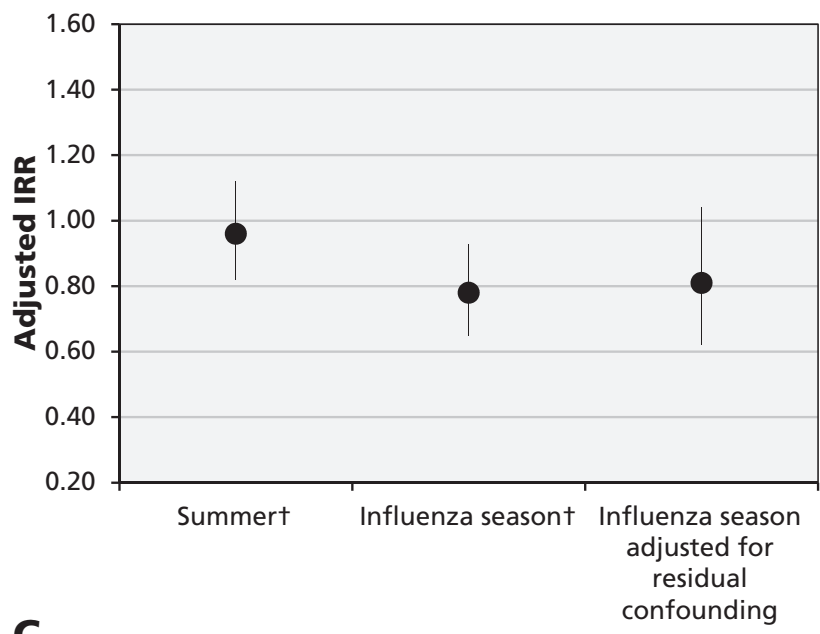

C

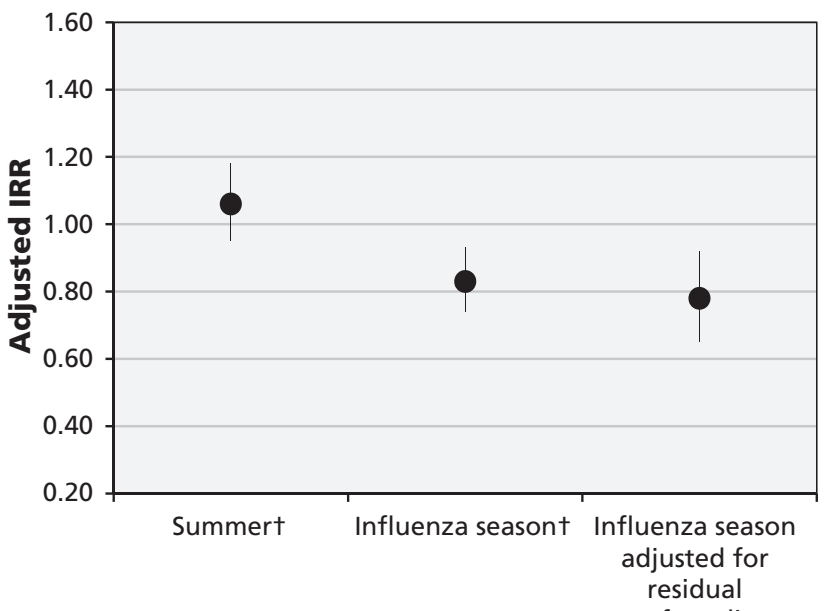

$\mathbf{E}$
B

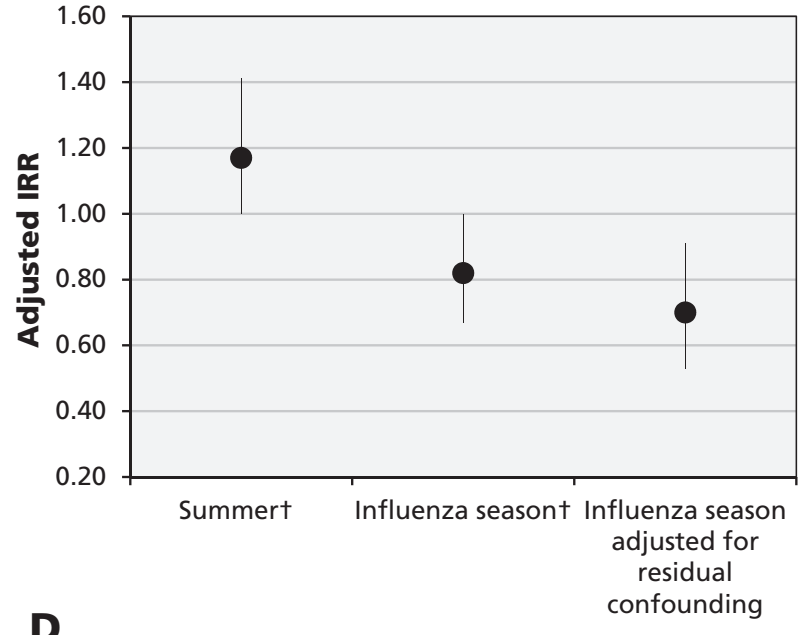

100

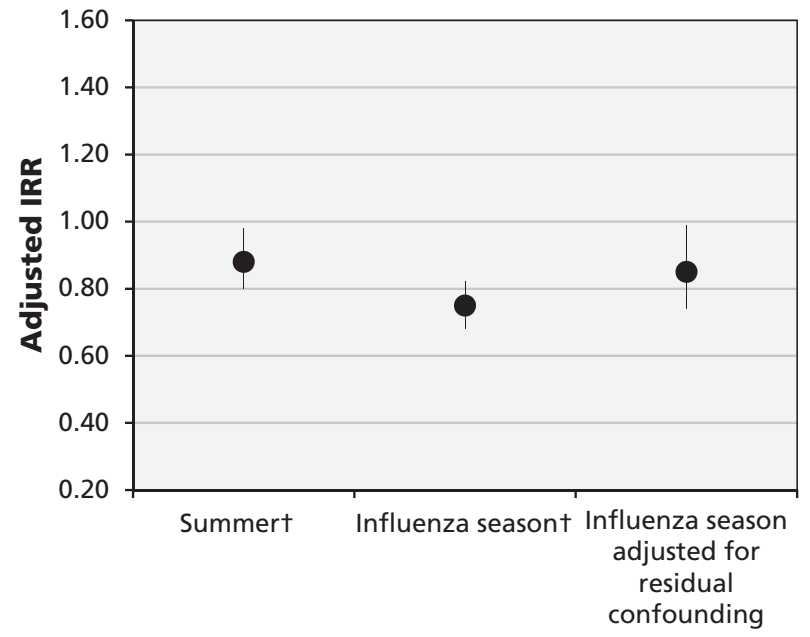

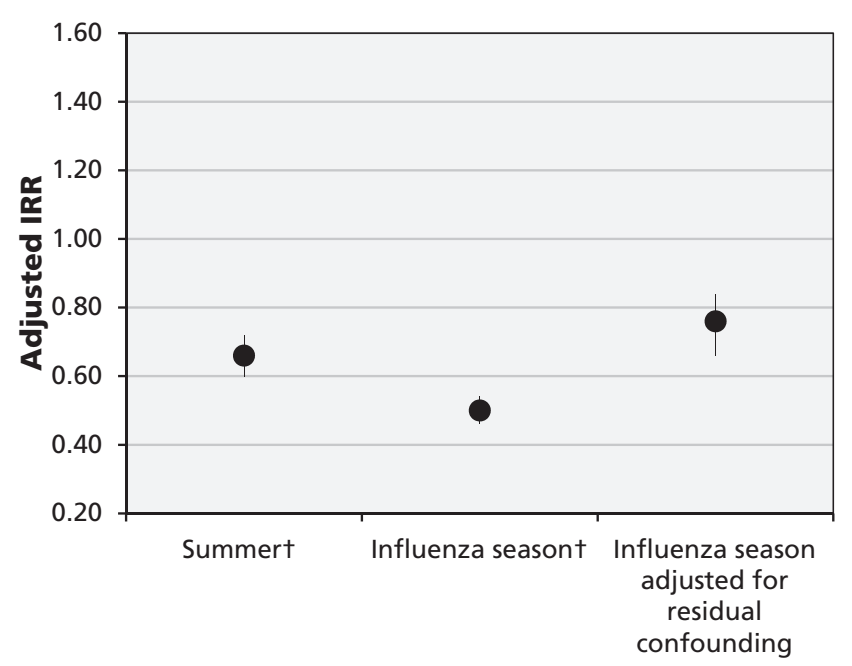

Figure 1: Association between influenza vaccination and study outcomes (A, myocardial infarction; B, stroke; C, hospital admission for heart failure; D, hospital admission for pneumonia or influenza; $E$, all-cause death) during the summer and influenza seasons, and after adjustment for residual confounding, in people with type 2 diabetes over 7 years. Error bars represent $95 \%$ confidence intervals; incident rate ratios (IRRs) of less than 1 indicate protection from vaccination. tModels were adjusted for age, sex, index of multiple deprivation quintile, number of comorbid conditions, duration of diabetes, body mass index, smoking status, systolic and diastolic blood pressure, serum cholesterol and glycated hemoglobin, use of lipid-lowering drugs, anticoagulant or antiplatelet drugs, antihypertensive drugs, insulin, oral antihyperglycemic drugs and immunosuppressive drugs, number of hospital admissions during the previous year, history of pneumococcal vaccination, influenza vaccination during the previous year and cohort year. 
vaccination was associated with lower rates of admission to hospital for acute MI, but this association was not statistically significant.

Current policy in many countries strongly emphasizes annual vaccination for older adults and patients with chronic conditions, such as diabetes. However, there is no conclusive clinical trial evidence to support the benefits of influenza vaccination in these groups. ${ }^{25}$ Epidemiologic studies quantifying influenza vaccine protection against severe outcomes for patients with diabetes are scarce and largely inconclusive. ${ }^{11} \mathrm{~A}$ recent meta-analysis found that, in patients with diabetes aged 18-64 years, influenza vaccine prevented $58 \%$ of all-cause admissions to hospital and $43 \%$ of admissions for influenza or pneumonia, but not death. ${ }^{11}$ In patients aged more than 65 years, the meta-analysis reported a pooled vaccine effectiveness of $38 \%$ for allcause death and $23 \%$ for all-cause admission to hospital. However, conclusions were limited by the small number of studies identified, lack of experimental studies, low quality of evidence and strong residual confounding in most studies. The authors did not identify any studies assessing influenza vaccine effectiveness against cardiovascular events.
To better account for the systematic differences between vaccine recipients and nonrecipients, we made additional adjustments for residual confounding using the summer period when minimal vaccine benefit is expected. ${ }^{13,23,24}$ Some authors have suggested using the preinfluenza season as a control period. Many previous studies assessing influenza vaccine effectiveness in older adults described reduced mortality associated with vaccination during the entire year. Often, the association was the largest before influenza was circulating. Jackson and colleagues argued that frail older adults in the US did not tend to receive influenza vaccine and died unvaccinated during follow-up. ${ }^{13}$ They concluded that, owing to this "frailty bias," pre-influenza periods are the most suitable for identifying residual confounding because the differences in risk between recipients and nonrecipients gradually decline with time. However, the pattern of vaccine uptake may largely differ in countries with different immunization strategies. In North America, influenza vaccine is universally recommended for all patients aged 6 months and older, but high-risk older adults in the US were found less likely to receive the vaccine. In England, although the national policy is to offer free influenza vaccine

Table 4: Risk of admission to hospital among people with type 2 diabetes who received influenza vaccination relative to people who did not receive vaccination for the influenza season and summer between 2003/04 and 2009/10 (excluding 2008/09, when the outbreak of pandemic A(H1N1)pdm09 occurred)

\begin{tabular}{|c|c|c|c|}
\hline \multirow[b]{2}{*}{ Outcome } & \multirow[b]{2}{*}{ Season* } & \multirow{2}{*}{$\begin{array}{c}\text { Unadjusted model } † \\
\text { IRR }(95 \% \mathrm{CI})\end{array}$} & \multirow{2}{*}{$\begin{array}{l}\text { Adjusted model } ¥ \\
\text { IRR }(95 \% \mathrm{CI})\end{array}$} \\
\hline & & & \\
\hline \multirow{2}{*}{$\begin{array}{l}\text { Hospital admissions for acute } \\
\text { myocardial infarction }\end{array}$} & Influenza & $1.17(1.01-1.36) \S$ & $0.76(0.62-0.93) \uparrow$ \\
\hline & Summer & $1.27(1.13-1.44)^{\star *}$ & $0.91(0.77-1.08)$ \\
\hline \multirow[t]{2}{*}{ Hospital admissions for stroke } & Influenza & $1.07(0.91-1.25)$ & $0.86(0.69-1.07)$ \\
\hline & Summer & $1.44(1.26-1.64) * *$ & $1.13(0.93-1.36)$ \\
\hline \multirow{2}{*}{$\begin{array}{l}\text { Hospital admission for heart } \\
\text { failure }\end{array}$} & Influenza & $1.25(1.14-1.38) * *$ & $0.82(0.72-0.93) \emptyset$ \\
\hline & Summer & $1.59(1.45-1.74) * *$ & $1.03(0.91-1.16)$ \\
\hline \multirow{2}{*}{$\begin{array}{l}\text { Hospital admission for } \\
\text { pneumonia/influenza }\end{array}$} & Influenza & $0.97(0.89-1.05)$ & $0.76(0.68-0.85)^{* *}$ \\
\hline & Summer & $1.19(1.09-1.28)^{\star *}$ & $0.89(0.79-0.99)^{*}$ \\
\hline \multirow[t]{2}{*}{ All-cause death } & Influenza & $0.87(0.81-0.93) * *$ & $0.52(0.47-0.58) * *$ \\
\hline & Summer & $1.14(1.08-1.21) * *$ & $0.67(0.61-0.73) * *$ \\
\hline \multicolumn{4}{|c|}{$\begin{array}{l}\text { Note: } \mathrm{Cl}=\text { confidence interval, IRR }=\text { incidence rate ratio. } \\
\text { *Influenza season was defined as the period from the onset to the end of the influenza season, with an additional } 4 \text { weeks to } \\
\text { capture delayed complications. Summer was defined as May } 1 \text { to Aug. } 31 \text { for each cohort year. } \\
\text { tModels with vaccination status as the only predictor. } \\
\text { fModels are adjusted for age, sex, index of multiple deprivation quintile, number of comorbid conditions, duration of } \\
\text { diabetes, body mass index, smoking status, systolic and diastolic blood pressure, serum cholesterol and glycated hemoglobin, } \\
\text { use of lipid-lowering drugs, anticoagulants or antiplatelet drugs, antihypertensive drugs, insulin, oral antihyperglycemic drugs } \\
\text { or immunosuppressive drugs, number of hospital admissions during previous year, history of pneumococcal vaccination, } \\
\text { influenza vaccination during previous year and cohort year. } \\
\$ p \leq 0.05 \text {. } \\
\text { Ip } \leq 0.01 \text {. } \\
* \star p \leq 0.001 \text {. }\end{array}$} \\
\hline
\end{tabular}


to all people with chronic conditions, the uptake increases with advancing age and the presence of comorbid conditions. ${ }^{26}$

Many previous studies examined influenza vaccine effectiveness by analyzing a single or a few seasons. ${ }^{27,28}$ There are large variations across years in influenza activity, pathogenicity of circulating strains and degree of vaccine-virus antigenic match. In 2003-2004, vaccine-virus antigenic match was low. An incompletely matched vaccine might provide protection against serologically confirmed influenza, but to a lesser extent than well-matched vaccines. ${ }^{21,29}$ Owing to these variations, evaluating vaccine effectiveness in individual seasons may yield widely ranging results on vaccine benefit. Our study provides valuable information on the long-term average benefits of influenza vaccine in people with type 2 diabetes.

In 2009, traditional influenza activity was low, but there was an outbreak of a pandemic influenza $\mathrm{A}(\mathrm{H} 1 \mathrm{~N} 1)$ pdm09 virus. ${ }^{18}$ Similarly to previous pandemics, this strain caused mild illness in most patients, and severe disease and death mostly occurred in children and young people..$^{30}$ Excluding 2008/09 from the analyses reduced statistical power because of the reduction in the number of events but did not change the associations found between vaccination and clinical outcomes.

\section{Strengths and limitations}

The strengths of this study include the use of a large population-based cohort of patients with type 2 diabetes, long follow-up time, the availability of key laboratory and clinical parameters, and knowing the exact dates of vaccination.

We were unable to evaluate misclassification of outcomes or covariates owing to undiagnosed cases of outcomes or comorbidity and unrecorded medical information. However, the validity of the Clinical Practice Research Datalink has been continuously monitored and evaluated as high for completeness and accuracy, and the database has been extensively used for health research. ${ }^{15}$ Furthermore, the study included cohort years during and after the introduction of the Quality and Outcomes Framework, when determination and recording of diabetes, comorbidities and vaccination status are likely to be more accurate owing to the financial incentive provided for general practitioners to record all cases. ${ }^{31}$ Uptake of influenza vaccine identified in this study is broadly consistent with published national data. ${ }^{26}$ Despite efforts to reduce the effect of selection bias between vaccine recipients and nonrecipients, adjustments undertaken using the summer estimates are unlikely to eliminate residual confounding.

\section{Conclusion}

Concerns about the benefits of influenza vaccination in older adults and patients with chronic illnesses affect the acceptance and uptake of influenza vaccination in many countries, including those with comprehensive immunization programs. ${ }^{25}$ This study has shown that people with type 2 diabetes may derive substantial benefits from current vaccines, including protection against hospital admission for some major cardiovascular outcomes. These findings underline the importance of influenza vaccination as part of comprehensive secondary prevention in this high-risk population.

\section{References}

1. Tillett HE, Smith JW, Clifford RE. Excess morbidity and mortality associated with influenza in England and Wales. Lancet 1980;1:793-5.

2. Thompson WW, Shay DK, Weintraub E, et al. Mortality associated with influenza and respiratory syncytial virus in the united states. JAMA 2003;289:179-86.

3. Simonsen L, Clarke MJ, Williamson GD, et al. The impact of influenza epidemics on mortality: introducing a severity index. Am J Public Health 1997;87:1944-50.

4. Warren-Gash C, Smeeth L, Hayward AC. Influenza as a trigger for acute myocardial infarction or death from cardiovascular disease: a systematic review. Lancet Infect Dis 2009;9:601-10.

5. Davenport FM. Control of influenza. Med J Aust 1973;(Suppl): 33-8.

6. Mereckiene J, Cotter S, Nicoll A, et al. Seasonal influenza immunization in Europe. Overview of recommendations and vaccination coverage for three seasons: pre-pandemic (2008/09), pandemic (2009/10) and post-pandemic (2010/11). Euro Surveill 2014;19:20780.

7. Statement on seasonal influenza vaccine for 2014-2015. Ottawa: Public Health Agency of Canada; 2015. Available: www.phac-aspc.gc.ca/naci-ccni/flu-grippe-eng.php (accessed 2015 Dec. 17).

8. Grohskopf LA, Sokolow LZ, Olsen SJ, et al. Prevention and control of influenza with vaccines: recommendations of the Advisory Committee on Immunization Practices, United States, 2015-16 influenza season. Am J Transplant 2015;15:2767-75.

9. Simonsen L, Taylor RJ, Viboud C, et al. Mortality benefits of influenza vaccination in elderly people: an ongoing controversy. Lancet Infect Dis 2007;7:658-66.

10. Osterholm MT, Kelley NS, Sommer A, et al. Efficacy and effectiveness of influenza vaccines: a systematic review and meta-analysis. Lancet Infect Dis 2012;12:36-44.

11. Remschmidt C, Wichmann O, Harder T. Vaccines for the prevention of seasonal influenza in patients with diabetes: systematic review and meta-analysis. BMC Med 2015;13:53.

12. Udell JA, Zawi R, Bhatt DL, et al. Association between influenza vaccination and cardiovascular outcomes in high-risk patients: a meta-analysis. JAMA 2013;310:1711-20.

13. Jackson ML, Yu O, Nelson JC, et al. Further evidence for bias in observational studies of influenza vaccine effectiveness: the 2009 influenza A(H1N1) pandemic. Am J Epidemiol 2013;178: 1327-36.

14. Phrommintikul A, Kuanprasert S, Wongcharoen W, et al. Influenza vaccination reduces cardiovascular events in patients with acute coronary syndrome. Eur Heart J 2011;32:1730-5.

15. Herrett E, Thomas SL, Schoonen WM, et al. Validation and validity of diagnoses in the general practice research database: a systematic review. Br J Clin Pharmacol 2010;69:4-14.

16. Williams T, van Staa T, Puri S, et al. Recent advances in the utility and use of the general practice research database as an example of a UK primary care data resource. Ther Adv Drug Saf 2012;3:89-99.

17. Gray J, Orr D, Majeed A. Use of read codes in diabetes management in a south london primary care group: implications for establishing disease registers. BMJ 2003;326:1130.

18. Official statistics: weekly national flu reports. London (UK): Health Protection Agency. Available: www.Hpa.Org.Uk/topics/ infectiousdiseases/infectionsaz/seasonalinfluenza/epidemiologic aldata/05influsweeklyinfluenzareportsarchive/ (accessed 2015 Mar. 10). 
19. Goddard NL, Kyncl J, Watson JM. Appropriateness of thresholds currently used to describe influenza activity in England. Commun Dis Public Health 2003;6:238-45.

20. Index of multiple deprivation 2004. London (UK): Department for communities and local government; 2004. Available: http:// data.Gov.Uk/dataset/imd_2004 (accessed 2015 Sept. 5).

21. Dean AS, Moffatt CR, Rosewell A, et al. Incompletely matched influenza vaccine still provides protection in frail elderly. Vaccine 2010;28:864-7.

22. Nichol KL, Nordin JD, Nelson DB, et al. Effectiveness of influenza vaccine in the community-dwelling elderly. $N$ Engl $J$ Med 2007;357:1373-81.

23. Groenwold RH, Hoes AW, Hak E. Impact of influenza vaccination on mortality risk among the elderly. Eur Respir J 2009;34:56-62.

24. Weiner MG, Xie D, Tannen RL. Replication of the Scandinavian simvastatin survival study using a primary care medical record database prompted exploration of a new method to address unmeasured confounding. Pharmacoepidemiol Drug Saf 2008;17:661-70.

25. Demicheli V, Rivetti D, Deeks JJ, et al. Vaccines for preventing influenza in healthy adults. Cochrane Database Syst Rev 2004;(3)CD001269.

26. HPA national influenza annual reports. London (UK): Health Protection Agency. Available: http://webarchive.Nationalarchives.Gov Uk/20140714084352/http://www.Hpa.Org.Uk/topics/infectiousdiseases/infectionsaz/seasonalinfluenza/epidemiologicaldata/07influsinf luenzaannualreports/ (accessed 2015 Dec. 17).

27. Jefferson T, Di Pietrantonj C, Al-Ansary LA, et al. Vaccines for preventing influenza in the elderly. Cochrane Database Syst Rev 2010;(2)CD004876.

28. Yao X, Hamilton RG, Weng NP, et al. Frailty is associated with impairment of vaccine-induced antibody response and increase in post-vaccination influenza infection in communitydwelling older adults. Vaccine 2011;29:5015-21.

29. Jefferson TO, Rivetti D, Di Pietrantonj C, et al. Vaccines for preventing influenza in healthy adults. Cochrane Database Syst Rev 2007;(2)CD001269.
30. Green HK, Andrews N, Fleming D, et al. Mortality attributable to influenza in England and Wales prior to, during and after the 2009 pandemic. PLoS One 2013;8:e79360.

31. Quality and outcomes framework. Leeds (UK): Health \& Social Care Information Centre. Available: www.Hscic.Gov.Uk/qof (accessed 2015 Dec. 10).

Affiliations: Department of Primary Care \& Public Health (Vamos, Pape, Curcin, Harris, Majeed, Millett), Imperial College London, London, UK; Department of Diabetes and Endocrinology (Valabhji), St Mary's Hospital, Imperial College Healthcare NHS Trust

Contributors: Eszter Vamos designed the study, analyzed the data and drafted the manuscript. Christopher Millett designed the study and cowrote the manuscript. Utz Pape and Vasa Curcin analyzed the data and wrote the manuscript. Azeem Majeed, Matthew Harris and Jonathan Valabhji contributed to the design of the study and revised the paper critically for important intellectual content. All of the authors approved the version to be published and agreed to act as guarantors of the work.

Acknowledgements: The Department of Primary Care andPublic Health at Imperial College is grateful for support from the National Institute of Health Research (NIHR) North West London Collaboration for Leadership in Applied Health Research and Care scheme, the NIHR Biomedical Research Centre scheme and the Imperial Centre for Patient Safety and Service Quality. Christopher Millett is funded by an NIHR Research Professorship.

Data sharing statement: Data are available from the Clinical Practice Research Datalink for additional analyses if necessary. 